Article

\title{
A Hybrid Fuzzy Analytic Hierarchy Process and the Technique for Order of Preference by Similarity to Ideal Solution Supplier Evaluation and Selection in the Food Processing Industry
}

\author{
Chia-Nan Wang ${ }^{1, *}$, Hsiung-Tien Tsai ${ }^{1, *}$, Van Thanh Nguyen ${ }^{2}$, Viet Tinh Nguyen ${ }^{2}$ \\ and Ying-Fang Huang ${ }^{1}$ \\ 1 Department of Industrial Engineering and Management, National Kaohsiung University of Science \\ and Technology, Kaohsiung 80778, Taiwan; winner@nkust.edu.tw \\ 2 Department of Logistics and Supply Chain Management, Hong Bang International University, \\ Ho Chi Minh 72320, Vietnam; thanhnv@hiu.vn (V.T.N.); tinhnv@hiu.vn (V.T.N.) \\ * Correspondence: cn.wang@nkust.edu.tw (C.-N.W.); hsiungtien@gmail.com (H.-T.T.)
}

Received: 20 December 2019; Accepted: 22 January 2020; Published: 2 February 2020

\begin{abstract}
Selecting suppliers plays an important role in improving efficiency of supply chains. In the field of extraction of vegetable oil, one of the main submaterials is hexane solvent. Choosing a supplier of hexane solvent is a multicriteria decision-making task that decision-makers must have an understanding of the quantitative and qualitative elements for assessing the symmetrical impact of the criteria to reach the most accurate result. In this paper, the authors suggest a multicriteria decision-making (MCDM) model for $\mathrm{N}$-hexane solvent (C6H14) supplier evaluation and selection for vegetable oil production. All criteria affecting to the hexane solvent supplier evaluation and selection process are defined by experts. Then, a fuzzy analytic hierarchy process (FAHP) multicriteria comparative analysis method has been applied for determining the weight of all criteria. Finally, the technique for order of preference by similarity to ideal solution (TOPSIS) was applied to select the optimal hexane solvent supplier. As a result, decision making unit 003 (DMU3) is the optimal supplier. The contribution of this research is to propose an MCDM model for hexane solvent supplier selection in the food industry. The work also proposed a useful guideline for supplier evaluation and selection processes in other industries.
\end{abstract}

Keywords: fuzzy theory; fuzzy analytic hierarchy process; food industry; supplier selection; sustainability; multicriteria decision-making

\section{Introduction}

Oilseeds are a popular agricultural product and becoming increasingly important to the economy. The general trend in the world today is that the area for growing oilseed crops is constantly expanding, while the area of industrial oil plants is increasingly shrinking. This is due in part to the replacement of industrial oils with chemicals but is mainly due, however, to the important role of cooking oils in the body, which has been scientifically analyzed. Besides, oily seeds are a nutritious food source for people and pets [1]. Today, cooking oil production technology is developed from oil extraction to refining technology to produce oil of higher quality [2].

Oil extraction is based on the good solubility properties of vegetable oils in nonpolar organic solvents such as gasoline, hecxane, dicloetane, and, mainly, hexane. The transfer of oil distributed internally, as well as the outer surfaces of solid objects such as granules, distillation powders, oil drying 
into the liquid phase of the solvent, is a mass transfer process that occurs in the motion layer, based on the difference. The first concentration is raw material and outside flow [2].

$\mathrm{N}$-hexane (C6H14) is used to extract oil and nonpolar compounds from oil-containing foods and also helps to eliminate unwanted compounds present in the material [3]. In Vietnam, N-hexane solvents are subject to high import taxes, which forces vegetable oil producers to impose high prices on products, and are difficult to compete with other products [4]. Besides, the issue of sustainable development, e.g., green products, are of increasing concern for customers. Choosing green suppliers to realize the long-term sustainable development goals through reducing energy and production costs will, thereby, increase profits. The Lowell Center for Sustainable Production [5], defined sustainable manufacturing as "sustainable production is the creation of products and services using processes and systems," which includes:

$>$ No pollution;

$>$ Conserving energy and efficient use of natural resources;

$>$ Economic efficiency;

$>$ Safe and healthy for workers, community and consumers; and

$>$ Brings social and creative incentives to all workers.

In this view, sustainable development is the interaction and interdependence of the three systems, as follows [6]:

$\checkmark \quad$ Economic sustainability: Creating prosperity for the community and effective use for all economic activities. The core is that the vitality and development of the business and its activities must be sustained in the long term.

$\checkmark \quad$ Social sustainability: Respect for human rights and equality for all requires equitable benefit distribution, focusing on poverty reduction. Recognize and respect different cultures while avoiding any form of exploitation.

$\checkmark \quad$ Environmental sustainability: Protection and management of resources; minimize environmental pollution, thus conserving biodiversity and other natural assets.

Therefore, choosing a supplier of hexane solvent is a MCDM model It can be seen that selecting a supplier is complex in that decision-makers must have an understanding of the qualitative and quantitative features for assessing the symmetrical impact of the criteria to reach the most accurate results.

MCDM model refers to making decisions in the presence of multiple, usually conflicting, criteria [7]. MCDM also refers to choosing the best alternative from among a finite set of decision alternatives in terms of multiple, usually conflicting, criteria. The main steps in multicriteria decision-making are as follows [8]:

Step 1. Build a system of assessment criteria that links the system capabilities to the objectives, Step 2. Establish alternative systems for achieving the objectives (creating parallel options),

Step 3. Assess the options using the determined criteria,

Step 4. Apply one of the normative multiple criteria analysis methods,

Step 5. Obtain one option as the "optimal" alternative; and

Step 6. If the final optimal alternative is denied, collect new information and perform the next iteration of the multiple criteria optimization process.

There are many literatures in applying MCDM methods to many fields of business and engineering. Among these, MCDM methods have been widely utilized to assist solving supplier selection problems. In this paper, the authors proposed a MCDM model for for N-hexane solvent (C6H14) supplier evaluation and selection for vegetable oil production. In the first stage, all criteria affecting N-hexane solvent (C6H14) supplier evaluation and selection process are defined by experts and literature review. Although some researches have considered the applications of AHP in this field, very few 
works have attempted to solve this problem in a fuzzy environment. This is the reason why this research took a hybrid AHP with fuzzy logic theory approach to solve the supplier selection problem. Hybrid fuzzy set theory into the AHP model is a very useful tool for solving complex decision-making problems, with the existence of various qualitative criteria. Thus, an FAHP, multicriteria comparative analysis method has been utilized for calculating the weight of all criteria in the next stage. Finally, TOPSIS, a multicriteria decision analysis method, was applied for evaluating and selecting the optimal supplier in the final stage. The authors applied TOPSIS model iin this stage because this model is computationally simpler which is easier to use than other models. The best alternative must have the shortest geometric distance from the PIS and the longest geometric distance from NIS [8,9]. The next part of this paper will present literature reviews to support building MCDM model, methods of determining parameters of FAHP model, TOPSIS model. Discussions and conclusions are displayed at the end of the paper.

\section{Literature Reviews}

According to Kraljic [10], the strategic significance of procurement was recognized in the 1990s because of its immense impact on organizations performance. The increased focus on core competencies, due to competitive pressure, has resulted in boosted level of outsourcing non-core operations and made purchasing cost a major part of product cost in many industries (Ghodsypour et al., 1998) [11]. Inefficient supplier selection process will reduce the company profit and may cause loses (Xu et al., 2013) [12]. As such, the selection of suppliers is one of the most difficult decision to make and plays an important role in the success of organizations.

Currently, many researchers applied MCDM model for supplier selection process in various industry such as: P.K Humphreys et at. [13] proposed a MCDM model for integrating environmental factors for supplier selection. Junyi Chai et al. [14] have reviewed an application of decision-making techniques in supplier selection. Pandian Pitchipoo et al. [15] integrated decision model for evaluating suppliers by combining the FAHP and GRA.

Selim Zaim et al. [16] used FAHP model for solving the problem of complex multi-criteria decision-making for supplier selection process. N. Arunkumar et al. [17] proposed a new method to assist the supplier selection process using fuzzy alpha cut analysis. The paper utilizes triangular fuzzy number to express the subjective preferences of evaluators. Ali Nazeri et al. [18] proposed an integrated model for supplier evaluation and selection in supply chain management. In the first step, suppliers are assessed using qualitative criteria such as financial health, services level and loyalty with Fuzzy AHP and obtain their weights. Meanwhile, fuzzy logic and triangular fuzzy numbers are used to manage the vague nature of human judgement. In the second step, suppliers are evaluated and ranked using quantitative criteria such as cost, defect rate, and delay-considering company's situations and suppliers' limitations-and forming a multi objective linear programming (MOLP) model.

Wang et al. [19] suggested an MCDM model for sustainable supplier selection for edible oil production, using hybrid FAHP and green DEA model. The study utilizes a hybrid MCDM model, which uses a FAHP in combination with a GDEA method to calculate the weights of evaluation criteria for a supplier selection procedure based on the opinions of the procurement experts of company. Wang et al. [20] proposed a MCDM approach for supplier evaluation and selection in the rice supply chain. The authors utilize a FANP to evaluate and rank these criteria. Then, DEA models are used for evaluating potential suppliers. Govidan et al. [21] developed a hybrid MCDM model to support supplier evaluation and selection process using fuzzy Delphi, DEMATEL, ANP and PROMETHEE; based on suppliers' corporate social responsibility practices. Awasthi et al. [22] developed a fuzzy AHP and VIKOR model to assist multi-tier global supplier selection process using sustainability criteria. Chen et al. [23] proposed a fuzzy approach for supplier evaluation and selection. The authors use trapezoidal fuzzy numbers to express linguistic ratings and build an MCDM model using on TOPSIS. Ziemba et al. [24] built a multi-criteria decision analysis to assist product evaluation process in online shopping comparison services. 
Rong-Ho Lin [25] proposed a hybrid FANP-MOLP model for supplier evaluation and order allocation. Ahmad Dargi et al. [26] applied Fuzzy-ANP approach model for supplier selection. The main goal of this paper is to develop a framework to support the supplier selection process in an Iranian automotive industry. Semih Önüt et al. [27] developed a supplier evaluation model using the ANP model and the TOPSIS method to help a telecommunication company in the GSM sector in Turkey. Bohui Pang et al. [28] suggested a fuzzy synthetic evaluation approach to assist the supplier selection process, which utilized analytic network process.

MCDM methods have been widely utilized to assist solving supplier selection problems over the years. Although some researches have considered the applications of AHP in this field, very few works have attempted to solve this problem in a fuzzy environment. This is the reason why this research took a hybrid AHP with fuzzy logic theory approach to develop a MCDM model for N-hexane solvent (C6H14) supplier evaluation and selection in the food processing industry.

\section{Methodology}

\subsection{Research Process}

In this research, the authors developed a MCDM model for hexane solvent (C6H14) supplier evaluation and selection process in the food processing industry. There are three main stages in this study (Figure 1):

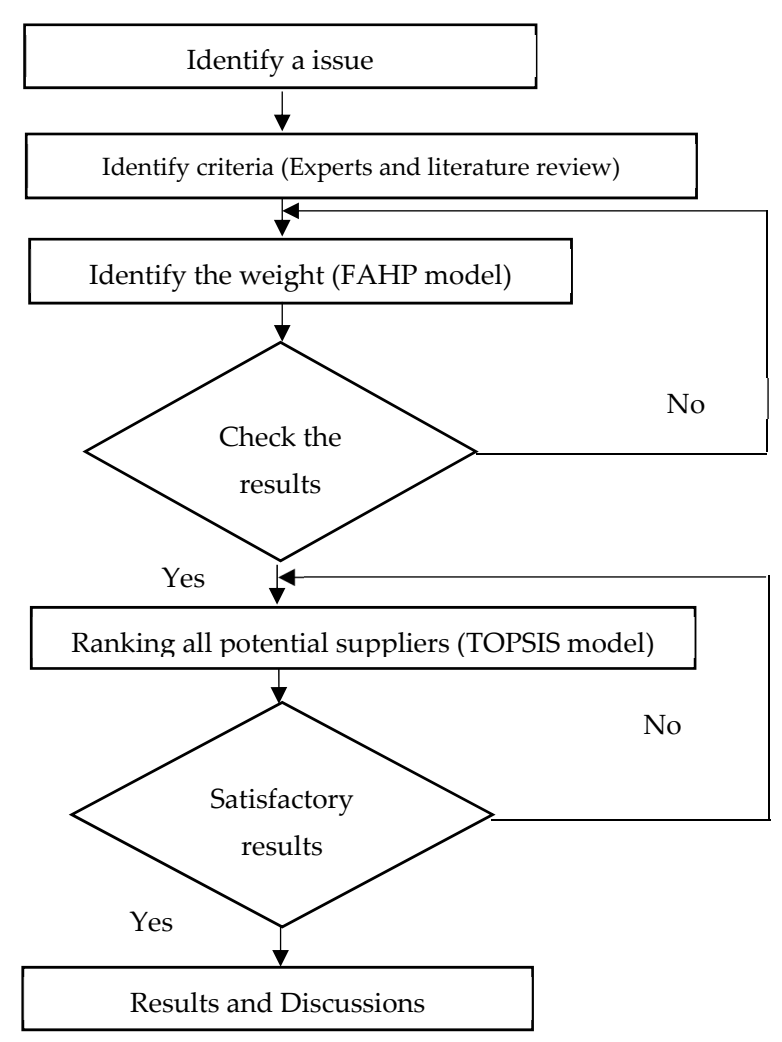

Figure 1. Research methodology.

All main criteria and subcriteria that affect hexane solvent (C6H14) supplier evaluation and selection process are defined by experts and literature review.

FAHP is utilized to determine the weight of the subcriteria.

TOPSIS is utilized to rank all potential suppliers. The optimal hexane solvent supplier is determined based on PIS and NIS values. 


\subsection{A Hybrid Model for Supplier Selection}

\subsubsection{FAHP Model}

- Fuzzy sets and fuzzy number

Fuzzy set was proposed by Zadeh (1965) [29] in order to solve problems in uncertain environments. Fuzzy set allows the gradual assessment of the set members with the use of membership function, valued within the interval $[0,1][30,31]$. The TFN can be defined as $(v, b, n)$. Theses numbers $(v \leq b \leq n)$, specify the smallest, the promising and the largest value. Figure 2.

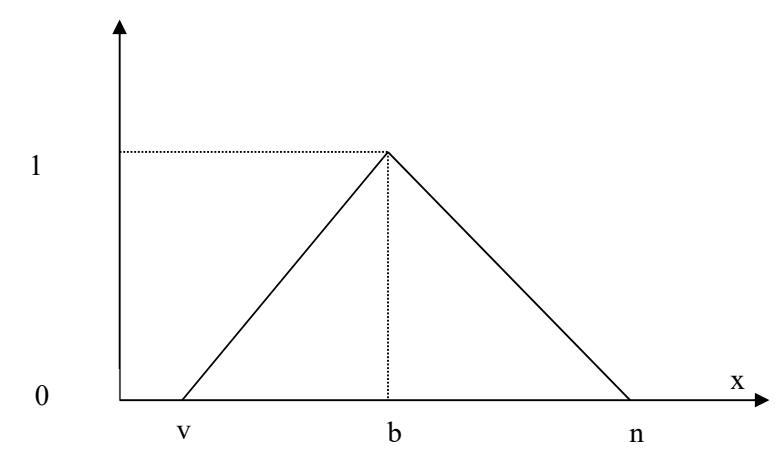

Figure 2. Traingular Fuzzy Number [32].

TFN can be defined as:

$$
\mu\left(\frac{x}{\widetilde{M}}\right)=\left\{\begin{array}{cc}
0, & x<b, \\
\frac{x-v}{b-v} & v \leq x \leq b, \\
\frac{n-x}{n-b} & b \leq x \leq n, \\
0, & x>u,
\end{array}\right.
$$

A Fuzzy number is calculated by the representatives of each level of membership as followed:

$$
\widetilde{M}=\left(M^{l(y)}, M^{r(y)}\right)=[v+(b-v) y, n+(b-n) y], y \in[0,1]
$$

$l(y), r(y)$ specify the left part and the right part of a fuzzy number, respectively. Two positive TFN $\left(v_{1}, b_{1}, n_{1}\right)$ and $\left(v_{2}, b_{2}, n_{2}\right)$ are shown as bellows:

$$
\begin{gathered}
\left(v_{1}, b_{1}, n_{1}\right)+\left(v_{2}, b_{2}, n_{2}\right)=\left(v_{1}+v_{2}, b_{1}+b_{2}, n_{1}+n_{2}\right) \\
\left(v_{1}, b_{1}, n_{1}\right)-\left(v_{2}, b_{2}, n_{2}\right)=\left(v_{1}-v_{2}, b_{1}-b_{2}, n_{1}-n_{2}\right) \\
\left(v_{1}, b_{1}, n_{1}\right) \times\left(v_{2}, b_{2}, n_{2}\right)=\left(v_{1} \times v_{2}, b_{1} \times b_{2}, n_{1} \times n_{2}\right) \\
\frac{\left(v_{1}, b_{1}, n_{1}\right)}{\left(v_{2}, b_{2}, n_{2}\right)}=\left(v_{1} / n_{2}, b_{1} / b_{2}, n_{1} / v_{2}\right)
\end{gathered}
$$

- Analytical hierarchy process (AHP)

The AHP method is a Multi Criteria Decision Making (MCDM) method, which was developped byProf. Thomas L. Saaty in the 1970s. The priorities of each level of hierachy, quantified by using a 1 to 9 Saaty scale, are determined by pairwise comparison matrixes.

\section{- Fuzzy AHP}

The weights of the criterias are calcualted by a eight-step-process using Fuzzy AHP:

Step 1: Triangle Fuzzy Number calculation

Criterias are compared in this step using pairwise comparision. The fuzzy analytical hierarchy process uses a combined range of values for evaluating criterias, instead of a single number [33]. The fuzzy conversion scale based on Parkash's fuzzy priortization method [34] will be used in this step: 
Step 2: $\widetilde{P}_{1}$ value calculation

After pairwise comparision is done, the relative scores are given as:

$$
\begin{gathered}
\widetilde{P}_{a}=\left(v_{a}, b_{a}, n_{a}\right) \\
v_{a}=\left(v_{a 1} \bigotimes v_{a 2} \bigotimes \ldots \bigotimes v_{a i}\right)^{\frac{1}{i}}, a=1,2, \ldots i \\
b_{a}=\left(b_{a 1} \bigotimes b_{a 2} \bigotimes \ldots \bigotimes b_{a i}\right)^{\frac{1}{i}}, a=1,2, \ldots i \\
n_{a}=\left(n_{a 1} \bigotimes n_{a 2} \bigotimes \ldots \bigotimes n_{a i}\right)^{\frac{1}{i}}, i=1,2, \ldots i
\end{gathered}
$$

Step 3: $\widetilde{P}_{Y}$ value calculation

The geometric fuzzy mean is calculated by (27):

$$
\widetilde{P}_{Y}=\left(\sum_{a=1}^{i} v_{a}, \sum_{a=1}^{i} b_{a}, \sum_{a=1}^{i} n_{a}\right)
$$

Step 4: $\widetilde{R}$ value calculation

The fuzzy geometric mean is calculated as:

$$
\widetilde{R}=\frac{\widetilde{P}_{a}}{\widetilde{P}_{Y}}=\frac{\left(v_{a}, b_{a}, n_{a}\right)}{\sum_{a=1}^{i} v_{a}, \sum_{a=1}^{i} b_{a}, \sum_{a=1}^{i} n_{i}}=\left[\frac{v_{a}}{\sum_{a=1}^{i} n_{a}}, \frac{b_{a}}{\sum_{a=1}^{i} b_{a}}, \frac{n_{a}}{\sum_{a=1}^{i} v_{a}}\right]
$$

Step 5: $w a_{\beta l}$ value calculation

Criterias, which are dependent of $\beta$ cut values, will be defined for the determined $\beta$. The fuzzy priorities are used for the lower $(l)$ and upper $(u)$ bounds of each $\beta o$ value:

$$
W a_{\beta l}=\left(W a l_{\beta l}, W a u_{\beta l}\right) ; a=1,2, \ldots i ; l=1,2, \ldots L
$$

Step 6: $W_{a l}$ and $W_{a u}$ values calculation

$W_{a l}$ and $W_{a u}$ are determined by summing the lower and the upper values, then dividing by the sum of $\beta$ values:

$$
\begin{gathered}
W_{a l}=\frac{\sum_{a=1}^{i} \beta\left(W_{a l}\right)_{l}}{\sum_{l=1}^{L} \beta_{l}} ; a=1,2, \ldots i ; l=1,2, \ldots L \\
W_{a u}=\frac{\sum_{a=1}^{i} \beta\left(w_{a u}\right)_{l}}{\sum_{l=1}^{L} \beta_{l}} ; a=1,2, \ldots i ; l=1,2, \ldots L
\end{gathered}
$$

Step 7: $W_{a d}$ value calculation

$W_{a d}$ is calculated by summing the upper and the lower bounds values, and use optimism index ( $\delta)$ to defuzzify.

$$
W_{a d}=\delta \cdot W_{a u}+(1-\delta) \cdot W_{a l} ; \delta \in[0,1] ; a=1,2, \ldots i
$$

Step 8: $W_{a z}$ value calculation 
Defuzzified priorities values are nomalized as:

$$
W_{a z}=\frac{W_{a d}}{\sum_{a=1}^{i} W_{a d}} ; a=1,2, . . i
$$

\subsubsection{TOPSIS}

The TOPSIS method proposed by Hwang and Yoon [8]. The main approach of TOSIS to MCDM problems is that the optimal option would have the shortest geometric distance from the PIS and the NIS [9]. With $m$ options and $n$ criterias, TOPSIS model result shows the score of each alternative [35,36]. The method is shown as followed:

Step 1: Normalized decision matrix is calculated, by converting raw values $\left(x_{a b}\right)$ to normalized values $\left(n_{a b}\right)$ as followed:

$$
n_{a b}=\frac{x_{a b}}{\sqrt{\sum_{a}^{g} x_{a b}^{2}}}, a=1, \ldots g ; b=1, . . h .
$$

Step 2: The weighted normalized value $\left(v_{a n}\right)$ is determined using:

$$
v_{a b}=P_{a b} n_{a b}, a=1, \ldots, g ; b=1, \ldots, h .
$$

with $P_{j}$ as the weight of the $a^{\text {th }}$ criterion, while $\sum_{b=1}^{h} p_{p}=1$.

Step 3: Determining PIS $\left(B^{+}\right)$and PIS $\left(B^{-}\right)$values, with $l_{a}^{+}$as the maximum value of $l_{a b}$, and $l_{a}^{-}$ as the minimum value $l_{a b}$.

$$
\begin{gathered}
B^{+}=\left\{l_{1}^{+}, \ldots, l_{h}^{+}\right\}=\left\{\left(\max _{b} l_{a b} \mid a \in A\right),\left(\min _{b} l_{a b} \mid a \in A\right)\right\}, \\
B^{-}=\left\{l_{1}^{-}, \ldots, l_{n}^{-}\right\}=\left\{\left(\min _{b} l_{a b} \mid a \in A\right),\left(\max _{b} l_{a b} \mid b \in B\right)\right\},
\end{gathered}
$$

where $\mathrm{A}$ is the 'relate with profit' criteria, and B is the 'relate with cost' criteria.

Step 4: Calculate the distance to the PIS $\left(D_{a}^{+}\right)$independently, using:

$$
D_{a}^{+}=\left\{\sum_{b=1}^{h}\left(l_{a b}-l_{b}^{+}\right)^{2}\right\}^{\frac{1}{2}}, a=1, \ldots, g
$$

Similarly, determine the distance from the NIS $\left(D_{i}^{-}\right)$using:

$$
D_{a}^{-}=\left\{\sum_{b=1}^{h}\left(l_{a b}-l_{b}^{-}\right)^{2}\right\}^{\frac{1}{2}}, a=1, \ldots, g
$$

Step 5: Identify the relationship proximal to the issue solving models, proximal relationship from option $B_{a}$ to option $B^{+}$

$$
C_{a}=\frac{D_{a}^{-}}{D_{a}^{+}+D_{a}^{-}}, a=1, \ldots, g .
$$

Step 6: Rank the options to get the best alternative with the highest $C_{a}$ value.

\section{Case Study}

$\mathrm{N}$-hexane (C6H14) is a vegetable oil extraction solvent. It helps to narrow the distillation range from extracted oils, with low aromatic content, thus eliminating unnecessary aromatic color content. Therefore, it is used as an extraction solvent of many vegetable oils such as soybean, coconut, peanut, palm, and healthy oils. 
Choosing the optimal N-hexane solvent (C6H14) supplier is critical to businesses in the food processing industry. Suppliers ensure that raw materials are in stable, accurate quantities and quality to meet operation requirements with reasonable cost and on-time delivery. Therefore, selecting an optimal supplier and managing it essential for the organization to produce a product of desired quality, on schedule, with a reasonable price and competitiveness in the market.

The suggested model is used to evaluate and selecting the optimal supplier among potential suppliers of N-hexane solvent of a famous food processing enterprise in Vietnam as a typical example to verify the model. After a preliminary assessment, ten potential suppliers (decision-makers [DMU]) were chosen by interviewing experts and head of purchasing departments based on production capacity, delivery time, quality of goods, supplier, and material prices. There are ten potential suppliers from $\mathrm{DMU}_{1}$ to $\mathrm{DMU}_{10}$ are considered in this research.

20 Experts and 05 head of purchasing departments have been interviewed for defining criteria affect to supplier selection processes. Table 1 shows the main criteria and sub-criteria used in this $\mathrm{N}$-hexane supplier selection process.

Table 1. Main and subcriteria for N-Hexane supplier selection process.

\begin{tabular}{ll}
\hline \multicolumn{1}{c}{ Main Criteria } & \multicolumn{1}{c}{ Subcriteria } \\
\hline & C11: Supplier's Capital and financial status \\
C1: Financial factors & C12: Prices of N-hexane \\
& C13: Transportation costs \\
& C21: Delivery solvent to factory \\
& C22: Customer services \\
& C23: Contact information systems \\
& C24: Production capacity \\
& C31: Quality of products \\
& C32: Operation control \\
& C33: Labor professionals, technical capabilities, and facilities \\
& C34: Experience and business position between competitors \\
& C41: Environmental emissions \\
& C42: Environmental planning \\
& C43: Environmentally friendly materials (packaging materials) \\
& C44: Environmentally friendly technology \\
\hline
\end{tabular}

After identifying important criteria and the potential suppliers, a fuzzy assessment matrix was developed. Then, the decision makers compared the elements that associate with the criteria. Pair comparison matrices and the weight vector of each matrix is then determined. Table 2 shows the weights of the criteria, calculated using FAHP.

Table 2. The weight of all subcriteria for N-Hexane supplier selection process.

\begin{tabular}{lc}
\multicolumn{1}{c}{ Subcriteria } & Weight \\
\hline C1.1: Supplier's Capital and financial status & 0.1157 \\
C1.2: Prices of N-hexane & 0.0540 \\
C1.3: Transportation costs & 0.1003 \\
C2.1: Delivery solvent to factory & 0.0344 \\
C2.2: Customer services & 0.0289 \\
C2.3: Contact information systems & 0.0104 \\
C2.4: Production capacity & 0.0279 \\
C3.1: Quality of products & 0.0344 \\
C3.2: Operation control & 0.0722 \\
C3.3: Labor professionals, technical capabilities, and facilities & 0.0692 \\
C3.4: Experience and business position between competitors & 0.0723 \\
C4.1: Environmental emissions & 0.0673 \\
C4.2: Environmental planning & 0.1083 \\
C4.3 Environmentally friendly materials (packaging materials) & 0.1186 \\
C4.4: Environmentally friendly technology & 0.0863 \\
\hline
\end{tabular}


Vietnam's food processing industry is facing many challenges, including domestic and global competition. In the past few years, Vietnam has joined several Free Trade Agreements. These agreements require businesses to improve not only product quality but also their production process. Among the requirements, environmental protection and sustainability are putting pressure upon local enterprise, which are used to lax regulation from the government. Also, financial success is vital to the survival of companies as well as their development and operation. Thus, environmental and financial factors are the most important conditional criteria and it is an expected result.

Finally, all ten potential suppliers will be ranked using a TOPSIS model. The Performance Matrix and the Normalized Weight Matrix are defined by TOPSIS model shown in Tables 3 and 4 .

Table 3. Performance Matrix.

\begin{tabular}{ccccccccccc}
\hline & DMU $_{\mathbf{1}}$ & $\mathbf{D M U}_{\mathbf{2}}$ & $\mathbf{D M U}_{\mathbf{3}}$ & $\mathbf{D M U}_{\mathbf{4}}$ & $\mathbf{D M U}_{\mathbf{5}}$ & $\mathbf{D M U}_{\mathbf{6}}$ & $\mathbf{D M U}_{\mathbf{7}}$ & DMU $_{\mathbf{8}}$ & DMU $_{\mathbf{9}}$ & DMU $_{\mathbf{1 0}}$ \\
\hline $\mathrm{C} 1.1$ & 6 & 7 & 8 & 8 & 9 & 7 & 6 & 8 & 8 & 9 \\
$\mathrm{C} 1.2$ & 8 & 8 & 7 & 9 & 8 & 6 & 8 & 9 & 8 & 9 \\
$\mathrm{C} 1.3$ & 8 & 7 & 9 & 6 & 7 & 8 & 9 & 8 & 8 & 8 \\
$\mathrm{C} 2.1$ & 9 & 8 & 8 & 7 & 9 & 8 & 9 & 8 & 8 & 8 \\
$\mathrm{C} 2.2$ & 8 & 8 & 7 & 9 & 8 & 7 & 7 & 8 & 9 & 9 \\
$\mathrm{C} 2.3$ & 7 & 7 & 8 & 9 & 7 & 6 & 8 & 9 & 8 & 9 \\
$\mathrm{C} 2.4$ & 9 & 8 & 8 & 8 & 7 & 8 & 9 & 9 & 9 & 9 \\
$\mathrm{C} 3.1$ & 9 & 8 & 9 & 7 & 9 & 8 & 9 & 8 & 7 & 6 \\
$\mathrm{C} 3.2$ & 8 & 8 & 7 & 9 & 9 & 8 & 8 & 7 & 8 & 9 \\
$\mathrm{C} 3.3$ & 8 & 7 & 8 & 9 & 8 & 8 & 9 & 8 & 9 & 9 \\
$\mathrm{C} 3.4$ & 7 & 8 & 8 & 9 & 8 & 9 & 8 & 8 & 7 & 7 \\
$\mathrm{C} 4.1$ & 8 & 8 & 9 & 8 & 8 & 8 & 7 & 7 & 9 & 9 \\
$\mathrm{C} 4.2$ & 8 & 9 & 8 & 9 & 7 & 8 & 9 & 7 & 8 & 8 \\
$\mathrm{C} 4.3$ & 8 & 7 & 8 & 9 & 8 & 8 & 9 & 8 & 7 & 7 \\
$\mathrm{C} 4.4$ & 8 & 7 & 8 & 9 & 8 & 8 & 9 & 8 & 9 & 9 \\
\hline
\end{tabular}

Table 4. The Normalized Weight Matrix.

\begin{tabular}{lllllllllll}
\hline & $\mathbf{D M U}_{\mathbf{1}}$ & $\mathbf{D M U}_{\mathbf{2}}$ & $\mathbf{D M U}_{\mathbf{3}}$ & $\mathbf{D M U}_{\mathbf{4}}$ & $\mathbf{D M U}_{\mathbf{5}}$ & $\mathbf{D M U}_{\mathbf{6}}$ & $\mathbf{D M U}_{\mathbf{7}}$ & $\mathbf{D M U}_{\mathbf{8}}$ & $\mathbf{D M U}_{\mathbf{9}}$ & $\mathbf{D M U}_{\mathbf{1 0}}$ \\
\hline $\mathrm{C} 1.1$ & 0.2474 & 0.2887 & 0.3299 & 0.3299 & 0.3712 & 0.2887 & 0.2474 & 0.3299 & 0.3299 & 0.3712 \\
$\mathrm{C} 1.2$ & 0.3143 & 0.3143 & 0.2750 & 0.3536 & 0.3143 & 0.2357 & 0.3143 & 0.3536 & 0.3143 & 0.3536 \\
$\mathrm{C} 1.3$ & 0.3223 & 0.2820 & 0.3626 & 0.2417 & 0.2820 & 0.3223 & 0.3626 & 0.3223 & 0.3223 & 0.3223 \\
$\mathrm{C} 2.1$ & 0.3462 & 0.3077 & 0.3077 & 0.2692 & 0.3462 & 0.3077 & 0.3462 & 0.3077 & 0.3077 & 0.3077 \\
$\mathrm{C} 2.2$ & 0.3148 & 0.3148 & 0.2754 & 0.3541 & 0.3148 & 0.2754 & 0.2754 & 0.3148 & 0.3541 & 0.3541 \\
$\mathrm{C} 2.3$ & 0.2816 & 0.2816 & 0.3218 & 0.3620 & 0.2816 & 0.2414 & 0.3218 & 0.3620 & 0.3218 & 0.3541 \\
$\mathrm{C} 2.4$ & 0.3378 & 0.3002 & 0.3002 & 0.3002 & 0.2627 & 0.3002 & 0.3378 & 0.3378 & 0.3378 & 0.3378 \\
$\mathrm{C} 3.1$ & 0.3530 & 0.3138 & 0.3530 & 0.2746 & 0.3530 & 0.3138 & 0.3530 & 0.3138 & 0.2746 & 0.2353 \\
$\mathrm{C} 3.2$ & 0.3112 & 0.3112 & 0.2723 & 0.3501 & 0.3501 & 0.3112 & 0.3112 & 0.2723 & 0.3112 & 0.3501 \\
$\mathrm{C} 3.3$ & 0.3039 & 0.2659 & 0.3039 & 0.3419 & 0.3039 & 0.3039 & 0.3419 & 0.3039 & 0.3419 & 0.3419 \\
$\mathrm{C} 3.4$ & 0.2791 & 0.3190 & 0.3190 & 0.3589 & 0.3190 & 0.3589 & 0.3190 & 0.3190 & 0.2791 & 0.2791 \\
$\mathrm{C} 4.1$ & 0.3112 & 0.3112 & 0.3501 & 0.3112 & 0.3112 & 0.3112 & 0.2723 & 0.2723 & 0.3501 & 0.3501 \\
$\mathrm{C} 4.2$ & 0.3112 & 0.3501 & 0.3112 & 0.3501 & 0.2723 & 0.3112 & 0.3501 & 0.2723 & 0.3112 & 0.3112 \\
$\mathrm{C} 4.3$ & 0.3190 & 0.2791 & 0.3190 & 0.3589 & 0.3190 & 0.3190 & 0.3589 & 0.3190 & 0.2791 & 0.2791 \\
$\mathrm{C} 4.4$ & 0.3039 & 0.2659 & 0.3039 & 0.3419 & 0.3039 & 0.3039 & 0.3419 & 0.3039 & 0.3419 & 0.3419 \\
\hline
\end{tabular}

The main approach of TOSIS to MCDM problems is that an optimal option will have the shortest geometric distance from the positive ideal solution (PIS) and the longest geometric distance from the negative ideal solution (NIS). As Figures 3 and 4, $\mathrm{DMU}_{3}$ has shortest geometric distance from the PIS and the longest geometric distance from the NIS. Thus, DMU3's winning factor in the final TOPSIS ranking. 


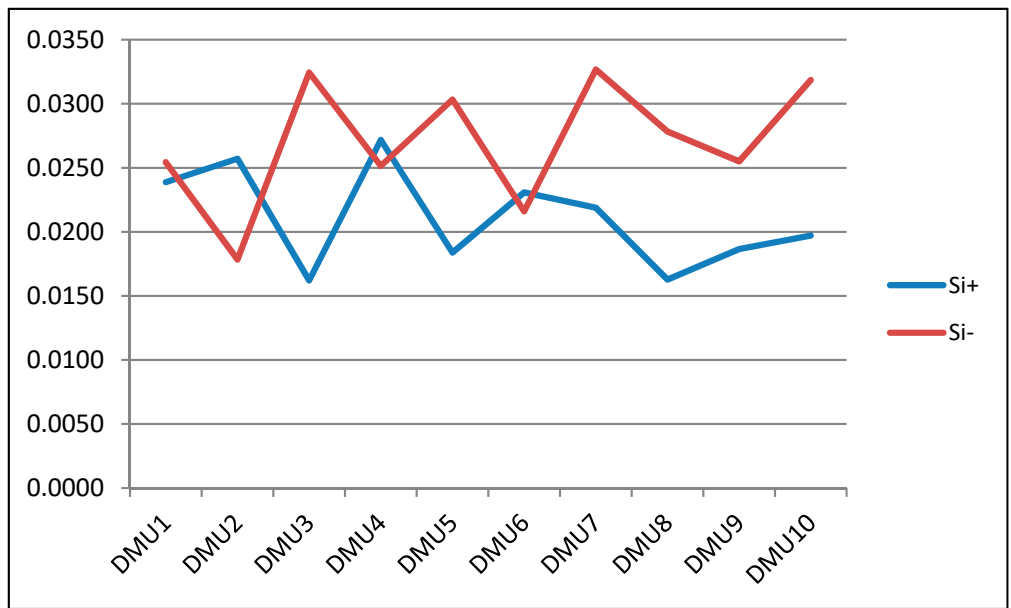

Figure 3. PIS and NIS from TOPSIS model.

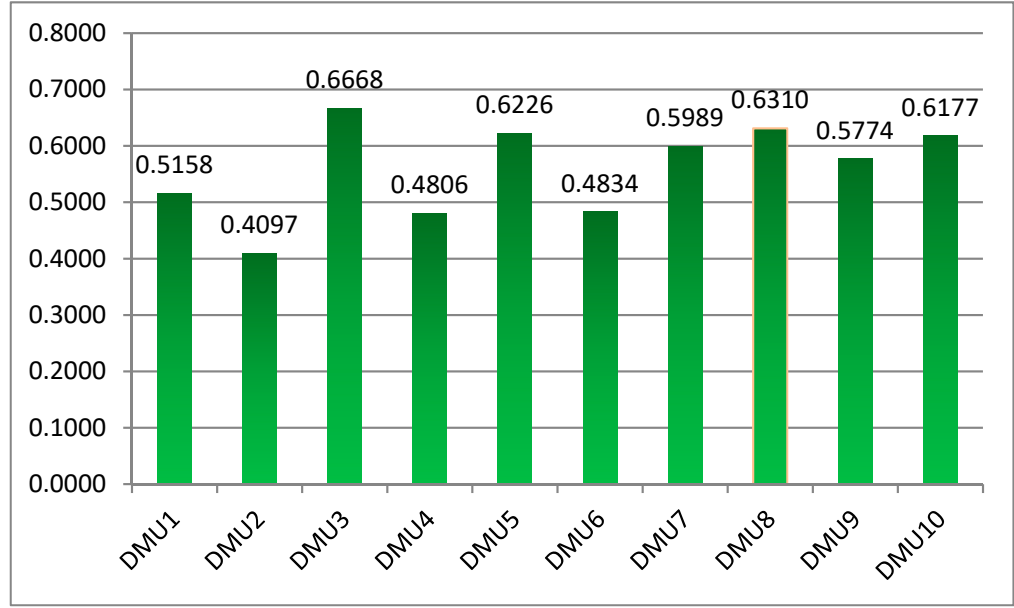

Figure 4. Final ranking score from TOPSIS.

In Figure 3, $\mathrm{DMU}_{3}$ has shortest geometric distance from the PIS and the longest geometric distance from the NIS.

Figure 4 show the results of the TOPSIS model. Base on the final performance score $C_{-} a$; the final location ranking list are DMU3, DMU8, DMU5, DMU10, DMU7, DMU9, DMU1, DMU6, DMU4, and DMU2. The results show that DMU3 is the best $\mathrm{N}$-hexane solvent $(\mathrm{C} 6 \mathrm{H} 14)$ supplier in this case study.

\section{Conclusions}

It has become increasingly difficult to buy materials at acceptable prices from suppliers. The fact that companies, organizations, and businesses can reduce costs associated with purchasing goods and increase profits without having to increase sales or reduce the quality of products, managing supplier relationships thus remains a holistic approach to managing business interactions with organizations that provide goods and services.

However, choosing a sustainable N-hexane supplier to ensure human health and environmental protection remains a critical issue. Many MCDM models have been developed to solve decision-making problems in various scientific and technical fields, a trend that has increased over the years. Among these, MCDM models have proven to be very useful in assisting supplier selection processes. This paper examines this issue under uncertain environmental conditions, and $\mathrm{N}$-hexane (C6H14) supplier selection processes can be considered as an MCDM problem. 
In this paper, the authors proposed a multicriteria decision-making (MCDM) model for N-hexane solvent (C6H14) supplier evaluation and selection for vegetable oil production. In the first stage, all criteria affecting supplier evaluation and selection process are defined by experts and literature review. Then, an FAHP is utilized for determining the weight of all criteria. Finally, TOPSIS is applied for ranking the potential suppliers.

The contribution of this research is to propose an MCDM model to assist the hexane solvent supplier selection process in vegetable oil production. The work also proposed a helpful guideline for supplier selection processes in other industries such as garment industry, mechanical industry.

The limitation of this study is the lack of specific main criteria and sub-criteria of social sustainability. It is suggested that future studies should focus on the development of new criteria, sub-criteria and the incorporation of new models and approaches such as Fuzzy TOPSIS, FANP, for other fields within the supplier evaluation and selection issue.

Author Contributions: Conceptualization, C.-N.W. and Y.-F.H.; Data curation, C.-N.W., H.-T.T., V.T.N. and Y.-F.H.; Formal analysis, V.T.N. and V.T.N.; Funding acquisition, V.T.N.; Investigation, C.-N.W. and Y.-F.H.; Methodology, H.-T.T., V.T.N. and V.T.N.; Project administration, H.-T.T., V.T.N. and V.T.N.; Resources, V.T.N. and V.T.N.; Software, C.-N.W.; Supervision, H.-T.T.; Writing—original draft, H.-T.T., V.T.N. and V.T.N.; Writing—review \& editing, C.-N.W. and Y.-F.H. All authors have read and agreed to the published version of the manuscript.

Funding: This research was partly supported by National Kaohsiung University of Science and Technology, and project number 108-2622-E-992-017-CC3 from the Ministry of Sciences and Technology in Taiwan.

Acknowledgments: The authors appreciate the support from National Kaohsiung University of Science and Technology, Hong Bang International University, Ministry of Sciences and Technology in Taiwan.

Conflicts of Interest: The authors declare no conflict of interest.

\section{References}

1. Durmaz, G.; Gokmen, V. Impacts of roasting oily seeds and nuts on their. Lipid Technol. 2010, $22,179$. [CrossRef]

2. Tan An, L.C. QUY TRÌNH CÔNG NGHỆ SẢN XUẤT DẦU ĂN. Available online: https://thegioimayepdau. com/quy-trinh-cong-nghe-san-xuat-dau-an/ (accessed on 15 February 2017).

3. Nguyen, T.P.Q. Dau An Va Suc Khoe-Ky 1: Hexane Trong San Pham Dau An Co Gay Doc Hay Khong. Available online: https://thucphamcongdong.vn/dau-va-suc-khoe-8-b-1-1.html (accessed on 12 January 2016).

4. Hoang, L. Giam Thue Nhap Khau Dung Moi N-Hexan Xuong 2\%. Available online: http://thoibaotaichinhvietnam. vn/pages/thue-voi-cuoc-song/2015-12-16/giam-thue-nhap-khau-dung-moi-n-hexan-xuong-2-27108.aspx (accessed on 16 December 2015).

5. Edwards, S. A New Way of Thinking: The Lowell Center Framework for Sustainable Products; University of Massachusetts Lowell: Lowell, MA, USA, 2009.

6. Vu,D.V. Tong quan ve phat trien ben vung. Available online: https://ditiep.com/tong-quan-ve-phat-trien-ben-vung/ (accessed on 7 July 2019).

7. Xu, L.; Yang, J.-B. Introduction to Multi-Criteria Decision Making. In Working Paper; Manchester School of Management: Manchester, UK, 2001.

8. Hwang, C.-L.; Yoon, K. Multiple Attribute Decision Making Methods and Applications A State-of-the-Art Survey; Springer: Berlin/Heidelberg, Germany, 1981.

9. Assari, A.; Maheshand, T.M.; Assari, E. Role of public participation in sustainability of historical city: Usage of TOPSIS method. Indian J. Sci. Technol. 2012, 5, 2289.

10. Kraljic, P. Purchasing must become supply management. Harv. Bus. Rev. 1983, 61, 109.

11. Ghodsypour, S.; O'Brien, C. A decision support system for supplier selection using an integrated analytic hierarchy process and linear programming. Int. J. Prod. Econ. 1998, 56, 199-212. [CrossRef]

12. Xu, L.; Kumar, D.; Shankar, T.; Kannan, K.; Chen, M. Analyzing criteria and sub-criteria for the corporate social responsibility-based supplier selection process using AHP. Int. J. Adv. Manuf. Technol. 2013, 68, 907-916. [CrossRef]

13. Humphreys, P.K.; Wong, Y.K.; Chan, F.T.S. Integrating environmental criteria into the supplier selection process. J. Mater. Process. Technol. 2003, 138, 349-356. [CrossRef] 
14. Chai, J.; Liu, J.N.K.; Ngai, E.W.T. Application of decision-making techniques in supplier selection: A systematic review of literature. Expert Syst. Appl. 2013, 40, 3872-3885. [CrossRef]

15. Pitchipoo, P.; Ponnusamy, V.; Sivaprakasam, R. Fuzzy hybrid decision model for supplier evaluation and selection. Int. J. Prod. Res. 2013, 51, 3903-3919. [CrossRef]

16. Zaim, S.; Sevkli, M.; Tarim, M. Fuzzy Analytic Hierarchy Based Approach for Supplier Selection. J. Euromarketing 2003, 12, 147-176. [CrossRef]

17. Arunkumar, N.; Karunamoorthy, L.; Muthukumar, S. Multi-criteria supplier evaluation and selection using fuzzy AHP (alpha cut analysis): A case study. Int. J. Ind. Syst. Eng. 2011, 8, 449-471. [CrossRef]

18. Nazeri, A.; Meftahi, H.; Shaharoun, A. Supplier Evaluation and Selection in SCM using Fuzzy AHP. In 3rd International Conference on Advanced Management Science; IACSIT Press: Singapore, 2011.

19. Wang, C.; Nguyen, V.T.; Thai, N.; Tran, N.; Tran, A. Sustainable Supplier Selection Process in Edible Oil Production by a Hybrid Fuzzy Analytical Hierarchy Process and Green Data Envelopment Analysis for the SMEs Food Processing Industry. Mathematics 2018, 6, 302. [CrossRef]

20. Wang, C.; Nguyen, V.T.; Duy, D.; Do, H. A Hybrid Fuzzy Analytic Network Process (FANP) and Data Envelopment Analysis (DEA) Approach for Supplier Evaluation and Selection in the Rice Supply Chain. Symmetry 2018, 10, 221. [CrossRef]

21. Govindan, K.; Shankar, M.; Kannan, D. Supplier selection based on corporate social responsibility practices. Int. J. Prod. Econ. 2018, 200, 353-379. [CrossRef]

22. Awasthi, A.; Govindan, K.; Gold, S. Multi-tier sustainable global supplier selection using a fuzzy AHP-VIKOR based approach. Int. J. Prod. Econ. 2018, 195, 106-117. [CrossRef]

23. Chen, C.-T.; Lin, C.-T.; Huang, S.-F. A fuzzy approach for supplier evaluation and selection in supply chain management. Int. J. Prod. Econ. 2006, 102, 289-301. [CrossRef]

24. Ziemba, P.; Jankowski, J.; Watróbski, J. Online Comparison System with Certain and Uncertain Criteria Based on Multi-criteria Decision Analysis Method. In Proceedings of the Computational Collective Intelligence; Nguyen, N.T., Papadopoulos, G.A., Jędrzejowicz, P., Trawiński, B., Vossen, G., Eds.; Springer International Publishing: Berlin/Heidelberg, Germany, 2017; pp. 579-589.

25. Lin, R.-H. An integrated FANP-MOLP for supplier evaluation and order allocation. Appl. Math. Model. 2009, 33, 2730-2736. [CrossRef]

26. Dargi, A.; Anjomshoae, A.; Galankashi, M.R.; Memari, A.; Tap, M.B. Supplier Selection: A Fuzzy-ANP Approach. Procedia Comput. Sci. 2014, 31, 691-700. [CrossRef]

27. Önüt, S.; Kara, S.S.; Işik, E. Long term supplier selection using a combined fuzzy MCDM approach: A case study for a telecommunication company. Expert Syst. Appl. 2009, 36, 3887-3895. [CrossRef]

28. Pang, B.; Bai, S. An integrated fuzzy synthetic evaluation approach for supplier selection based on analytic network process. J. Intell. Manuf. 2013, 24, 163-174. [CrossRef]

29. Zadeh, L.A. Fuzzy Sets. Inf. Control 1965, 8, 338-358. [CrossRef]

30. Shu, M.H.; Cheng, C.H.; Chang, J.R. Using intuitionistic fuzzy sets for fault-tree analysis on printed circuit board assembly. Microelectron. Reliab. 2006, 46, 2139-2148. [CrossRef]

31. Kahraman, C.; Ruan, D.; Tolga, E. Capital budgeting techniques using discounted fuzzy versus probabilistic cash flows. Inf. Sci. 2002, 142, 57-76. [CrossRef]

32. Diouf, M.; Choonjong, K. Fuzzy AHP, DEA, and Managerial Analysis for Supplier Selection and Development; From the Perspective of Open Innovation. Sustainability 2018, 10, 3779. [CrossRef]

33. Kuswandari, R. Assessment of Different Methods for Measuring the Sustainability of Forest Management; International Institute for Geo-Information Science and Earth Observation: Enschede, The Netherlands, 2004.

34. Prakash, T.N. Land Suitability Analysis for Agricultural Crops: A Fuzzy Multi Criteria Decision Making Approach; International Institute for Geo-Information Science and Earth Observation: Enschede, The Netherlands, 2003.

35. Jahanshahloo, G.R.; Lotfi, F.H.; Izadikhah, M. Extension of the TOPSIS method for decision-making problems with fuzzy data. Appl. Math. Comput. 2006, 181, 1544-1551. [CrossRef]

36. Saaty, T.L. The Analytic Hierarchy Process; McGraw-Hill International: New York, NY, USA, 1980.

(C) 2020 by the authors. Licensee MDPI, Basel, Switzerland. This article is an open access article distributed under the terms and conditions of the Creative Commons Attribution (CC BY) license (http://creativecommons.org/licenses/by/4.0/). 